\title{
Educação inclusiva: para todos ou para cada um? Alguns paradoxos (in)convenientes
}

Kelly Cristina Brandão da Silva *

Entende-se por educação especial, para os efeitos desta Lei, a modalidade de educação escolar, oferecida preferencialmente na rede regular de ensino, para educandos porta-

dores de necessidades especiais

(Art. 58 - Lei n. 9394/96 - Lei de Diretrizes e Bases da

Educação Nacional - 1996)

Resumo: A educação inclusiva realmente instala um novo paradigma? Em um movimento para mascarar e recobrir a experiência de ambivalência e mal-estar suscitada pelo estranho, percebe-se uma tentativa de naturalizar as diferenças dos alunos com necessidades educativas especiais e enquadrá-los em categorias ordenadoras previamente estabelecidas, que pressupõem uma descrição detalhada e refinada, em um movimento classificatório que tende ao infinito. Os apelos contemporâneos ao individualismo e ao consumismo estão impregnados no discurso da educação inclusiva, perceptíveis na exacerbação do poder do especialista, na preocupação com a eficácia da educação e no excesso (de informações, de técnicas e de saberes).

Palavras-chave: educação inclusiva; psicanálise; estranho; especialista.

Inclusive education: Is it for everyone or for each one? Some (in)convenient paradoxes

Abstract: Does inclusive education actually set a new paradigm? In a move to mask and cover the experience of ambivalence and discomfort caused by the strange ones, we can observe an attempt to make the differences in students with special educational needs look lighter and fit them into previously established categories, which involve a detailed and refined description, in an endless classifying move. The contemporary appeals to individualism and consumerism are impregnated in the inclusive education discourse, and they are perceived in the exacerbation of specialist teachers' power, as well as in the concern about effectiveness in education and in some excess (of information, techniques and knowledge).

Key words: inclusive education; psychoanalysis; strange; specialist.

* Membro do Laboratório de Estudos e Pesquisas Psicanalíticas e Educacionais sobre a Infância (Lepsi) do Instituto de Psicologia e da Faculdade de Educação da Universidade de São Paulo (USP). Professora do curso de Psicologia da Universidade Metodista de São Paulo, SP, Brasil. kcbdasilva@usp.br

Pro-Posições, Campinas, v. 21, n. 1 (61), p. 163-178, jan./abr. 2010 
Freud, em Totem e tabu (1913), sustenta que a gênese da lei é o tabu, e este, por definição, é ambivalente. Ao ressaltar a origem primitiva do termo tabu sacer - e apontar que o significado diverge em dois sentidos contrários, por um lado "sagrado", "consagrado" e, por outro, "misterioso", "perigoso", "proibido", "impuro" (p. 38), Freud desmascara o caráter unívoco da lei. Segundo ele, "onde existe uma proibição tem de haver um desejo subjacente" (p. 92). Interessante a observação de Freud sobre as palavras primitivas. Estas comportavam um certo caráter onírico, com possibilidades ambíguas de significação. Como aponta o filósofo Giorgio Agamben,

Em 1910, Freud havia lido o ensaio de um linguista hoje desacreditado, K. Abel, sobre o Sentido contraditório das palavras originárias, e havia feito uma crítica sobre ele em um artigo na Imago, no qual coligava-o com a sua teoria da ausência do princípio de contradição nos sonhos (2004, p. 86, grifos do autor).

Com o advento da racionalidade, as palavras foram perdendo essa característica - numa tentativa de rompimento da ambivalência - e adquirindo, forçosamente, um caráter unívoco. No percurso da modernidade, percebe-se uma luta contra a ambivalência e a pretensão de anulá-la. Ainda em Totem e tabu, Freud já assinalava que a elaboração secundária, fruto de processos conscientes, tem a função de recobrir e mascarar os sentidos inconscientes - sempre ambivalentes - e, portanto, cumpre um papel de recalque. Nesse sentido, a ambivalência é irredutível.

Zygmunt Bauman, em seu texto Modernidade e ambivalência (1999), resgata o insuportável e o insustentável da experiência humana da ambivalência e a tentativa do seu apagamento através da elaboração secundária. "Se a modernidade diz respeito à produção da ordem, então a ambivalência é o refugo da modernidade." (p. 23). Esse autor discute o pensamento moderno, racional, categorial, que institui os amigos e os inimigos:

A oposição entre amigos e inimigos separa a verdade da falsidade, o bem do mal, a beleza da feiúra. Também diferencia entre o próprio e o impróprio, o certo e o errado, aquilo que é de bom gosto e o que não fica bem. Ela torna o mundo legível e, com isso, instrutivo. Ela dispersa a dúvida. E capacita o inteligente a prosseguir. Ela garante que se vá onde se deve ir. Ela faz a opção parecer reveladora da necessidade natural - de forma que a necessidade criada pelo homem possa ficar imune aos caprichos da escolha. (op. cit., p. 63).

Ao naturalizar a experiência humana, transformando opção (fruto da subjetividade) em necessidade natural, obturamos a ambivalência afetiva que caracte- 
riza o humano. Cabe aqui ressaltar o termo necessidade, tão presente no discurso oficial da educação inclusiva. Os alunos a serem incluídos no sistema regular de ensino são nomeados pela LDB de "educandos com necessidades educativas especiais".

Uma outra categoria descrita por Bauman é a do estranho - nem amigo, nem inimigo - e sujeito a todo e qualquer tipo de projeção. "Os indefiníveis expõem brutalmente o artifício, a fragilidade, a impostura da separação mais vital. Eles colocam o exterior dentro e envenenam o conforto da ordem com a suspeita do caos." (op. cit., p. 65). Como o estranho não se enquadra nas categorias existentes, causa tensão e ameaça. Mais uma vez, a negação da experiência da ambivalência. O autor expõe o "horror da indeterminação" (p. 67), retratado pela impossibilidade de classificação de alguns estranhos.

[...] Esses são os verdadeiros híbridos, os monstros - não apenas não classificados, mas inclassificáveis. Eles não questionam apenas uma oposição, aqui e ali: questionam a oposição como tal, o próprio princípio da oposição, a plausabilidade da dicotomia que ela sugere e a factibilidade da separação que exige. Desmascaram a frágil artificialidade da divisão. Eles destroem o mundo. Estendem a temporária inconveniência de "não saber como prosseguir" a uma paralisia terminal. Devem ser transformados em tabu, desarmados, suprimidos, física ou mentalmente exilados - ou o mundo pode perecer. (op. cit., p. 68, grifos do autor).

Freud, em 1919, escreve um texto intitulado "Das Unheimliche", um termo em alemão que comporta sentidos como: aquilo que é não familiar, indomesticado, estranho e inquietante. Cabe ressaltar que o radical heim significa lar, casa. Já o prefixo un- tem a função de negativa (como in na língua portuguesa). Devido a essa ambiguidade, alguns psicanalistas têm traduzido "Das Unheimliche" por estranho-familiar. Nesse texto Freud mostra que aquilo que se apresenta como estranho, aparentemente desconhecido, na verdade já foi conhecido um dia. A oposição aparente aponta - de forma paradoxal - uma equivalência entre estranho e familiar. "Das Unheimliche" seria a assustadora impressão que se liga às coisas conhecidas há muito tempo e familiares desde sempre e, nesse sentido, é o efeito do retorno do recalcado.

Avançando um pouco mais, é possível creditar à estrangeirice da criança uma fonte inesgotável de enigma para o adulto. De acordo com Lajonquière (2001):

O saber não sabido - mistério a ser contado - creditado na conta da criança faz dela um estrangeiro de quem queremos apre(e)nder suas histórias de um "outro mundo". Porém, o que de fato 
queremos, é impossível, pois trata-se de que nos revele essa estrangeirice que nos habita. D'isso só nós podemos "nos falar" a "nós" mesmos" na medida em que as crianças, permanecendo sempre um pouco estranhas a nós, nos devolvam - para assim podermos nos interrogar - o fato de sermos estrangeiros a nós mesmos. No entanto, o mal-entendido não aborta o diálogo, pelo contrário, o alimenta ao tempo que faz acontecer uma educação infantil. (p. 55, grifos do autor)

A perspectiva da educação inclusiva, ao propor a inclusão de alunos que antes não faziam parte do sistema regular, expõe - por um lado - uma contradição; afinal, se a educação é para todos, por que nem todos estavam lá? Mas, por outro lado, é rapidamente recalcada, em termos freudianos, pela elaboração secundária, dicotômica, categorial. Em um movimento para mascarar e recobrir a experiência de ambivalência e mal-estar suscitada pelo estranho que está entre nós, percebe-se uma tentativa de naturalizar as diferenças dos alunos com necessidades educativas especiais e enquadrá-los em categorias ordenadoras previamente estabelecidas, que pressupõem uma descrição detalhada e cada vez mais refinada, em um movimento classificatório que tende ao infinito.

Segundo o Corde ${ }^{1}$ (Decreto n. 3.298/99), "É considerada pessoa portadora de deficiência a que se enquadra nas seguintes categorias: deficiência física, auditiva, visual, mental e múltipla” (grifo meu). O Censo Escolar de 2006 (MEC/ Inep) registra que a participação da educação inclusiva cresceu no Brasil, passando dos 24,7\% em 2002, para 46,4\% em 2006, e distribui as deficiências nas seguintes categorias: cegueira, baixa visão, deficiência auditiva, surdez, surdo-cegueira, deficiência mental, deficiência múltipla, deficiência física, altas habilidades/superdotação, condutas típicas, autismo e síndrome de Down. O documento ainda alerta que existem doenças que são confundidas com deficiências e, portanto, merecem nova categorização. São elas: talassemina, autismo, distúrbio de comunicação (distúrbios de articulação, da voz, de linguagem; fissura labiopalatal; gagueira) e distúrbio de aprendizagem.

Se a criança sempre representou o estranho-familiar, talvez agora - na convivência com aqueles tidos com necessidades educativas especiais - o estranho sobressaia enormemente ao familiar. Não por acaso, o debate sobre a educação inclusiva tem aparecido de forma sempre polarizada. Ou se é contra ou a favor. Essa polarização obtura a complexidade em questão. De acordo com Voltolini (2006),

1. Coordenadoria Nacional para a Integração da Pessoa Portadora de Deficiência — Corde — é o órgão de Assessoria da Secretaria Especial dos Direitos Humanos da Presidência da República. 
por isso a discussão sobre inclusão tende a transcorrer mais como um debate (ou combate) onde o importante é a defesa de opinióes e menos como um enfrentamento do real, neste caso o real da diferença irredutivel destes indivíduos, impossivel de ser eliminado seja com a política da escola especial, seja com a política da escola inclusiva. (grifos do autor)

Retomando Bauman (1999), este considera que a convivência com a ambivalência seria mais suportável na experiência da pluralidade. Esta pressupõe descentramento, indeterminação. Não parece ser esse o ideal da educação inclusiva. A tendência classificatória presente nos documentos oficiais obtura ainda mais a falta, a incompletude, a ambivalência - características inerentes ao ser falante - transformando os incluidos em tabu. Citando Bauman,

Os estranhos recusavam-se a serem divididos claramente em 'nós' e 'eles', amigos e inimigos. Teimosa e irritantemente, eles permaneciam indeterminados - seu número e poder de aborrecer parecem crescer com a intensidade dos esforços para dicotomizar. (op. cit., p. 75, grifos do autor).

Lacan (1992), no seminário 17, O avesso da psicanálise, analisa o discurso do mestre como fruto do recalque dos processos oníricos, inconscientes. No discurso do mestre há a busca pela univocidade e pela dicotomia ("ou isto ou aquilo"). A radicalidade da descoberta da psicanálise - o inconsciente - colocaa, segundo Lacan, como o avesso do discurso do mestre. É tarefa da psicanálise apontar o discurso do mestre, rompendo com as dicotomias e tornando o debate mais complexo. Segundo Serge André (1998), a psicanálise propõe uma relação diferente com o saber. Normalmente pensado como algo exato, unívoco e tangível, o saber - na atualidade - acumula-se, está disponível, transbordante e acessível a todos e, paradoxalmente, não tem mais efeito algum sobre ninguém. A psicanálise, na contramão, expõe um saber que nos implica.

O saber psicanalítico não funciona, assim, em posição da verdade, a não ser na medida em que opera como saber furado, afetado por uma falha central - o que determina o estatuto da verdade enquanto semi-dizer. A psicanálise não permite saber tudo, pois o inconsciente não diz tudo. Lacan nos convida a compreender que essa falha não é da ordem de uma imperfeição que os progressos da pesquisa permitiriam preencher, mas sim que ela constitui a chave para a própria estrutura do saber. Convém, pois, dar forma afirmativa a nossa proposição: a psicanálise permite saber o "não-todo", porque o inconsciente diz "não-todo" (André, 1998, p. 10, grifos do autor). 
Freud, ao estudar os atos falhos, já nos apontava que é no lapso, no erro, que melhor confessamos o verdadeiro. E com Lacan aprendemos que a verdade tem estrutura de ficção. Voltolini (2006) ressalta o caráter atópico da psicanálise, em oposição às utopias que desfilam na pedagogia:

Talvez se possa esperar que a partir justamente de sua atopia a psicanálise possa entrar aí, não para debater, o que só repetiria o jogo da polarização, mas para confrontar com esse real, o que sempre lhe é mais característico. Se assim for ela pode funcionar como esse terceiro que entra para esvaziar o campo das certezas (opiniōes), das garantias para instalar o campo das interrogaçōes da causação do desejo de saber.

Em uma reportagem de capa da revista Nova Escola² (Guimarães, 2003), intitulada "A inclusão que funciona" (já chama a atenção o caráter funcional que o título sugere) recomenda-se aos professores um site na internet - Entre amigos $^{3}$ - com informações sobre associações especializadas. A revista disponibiliza um link que dá acesso direto à página do referido site, que contém 149 associaçõos que tratam de diferentes deficiências, tais como: esclerose múltipla, síndrome de Angelman, distrofia muscular, paraplegia, deficiência física, autismo, autismo de alto desempenho, síndrome de Down, deficiência visual, surdez, deficiência de hormônio do crescimento, deficiência mental, transtorno do deficit de atenção e hiperatividade, síndrome de Prader Willi, síndrome de Williams, visão subnormal.

É fácil entender por que uma das reclamações dos professores, em relação à inclusão, é justamente a falta de conhecimento específico. Ora, se a referida mídia ${ }^{4}$ privilegia o acesso - e o excesso - às informaçōes especializadas, justifica-se a queixa. Os próprios documentos oficiais ressaltam a relevância da identificação das necessidades especiais, determinadas antecipadamente, e não $a$ posteriori. Isso necessariamente facilitaria o processo ensino-aprendizagem, pois sabe-se previamente o que e como fazer. O planejamento e a metodologia, baseados nesses parâmetros, são norteadores seguros que objetivam o desenvolvimento das potencialidades dos alunos, como preconiza a nova LDB. A educa-

2. Nova Escola é editada em São Paulo pela Fundação Victor Civita, do Grupo Abril. Trata-se de publicação mensal, que até o ano de 1997 circulou em nove edições anuais e que a partir de 1998 tem circulado em dez edições por ano.

3. Entre amigos - Rede de Informações sobre Deficiência.

Disponível em: <http://www.entreamigos.com.br/links.html > . Acesso em: 30 de setembro de 2008.

4. Nova Escola é subsidiada através de parcerias com o governo federal, o que tem permitido sua distribuição gratuita às escolas públicas brasileiras. Publicada desde 1986, vem se constituindo como um importante veículo de divulgação de ideias e práticas pedagógicas para os professores. 
ção para todos, transforma-se - paradoxalmente — em educação para cada um.

O professor, diante da profusão de informaçôes, vê-se incapacitado (daí a proliferação de cursos de capacitação) e desatualizado (por isso a frenética busca por cursos de atualização). O que se pretende interrogar aqui é a voracidade que está em jogo. Não basta saber algo, temos que saber tudo. Nesse movimento, o conhecimento é permanentemente renovável, substituído, descartável - como o lixo (para isso há os cursos de reciclagem). Os professores, diante da impossibilidade estrutural de apre(e)nder tudo, tornam-se eternos alunos (daí a importância da formação continuada).

A psicanálise destaca que o recalcado retorna. Talvez um dos efeitos desse apagamento do lugar do professor apareça atualmente em forma de um voyeurismo, diria quase pornográfico, na relação da escola com os alunos e as suas famílias. Para educar bem, é preciso conhecer o aluno (e também sua família), estabelecer um vínculo, saber seu histórico de vida, desnudá-lo em seus aspectos biopsicossociais (daí a crescente demanda por laudos e diagnósticos médicos e psicológicos). Interessante notar um termo relativamente novo utilizado pela escola para referir-se aos contatos que ela tem com as famílias. Se antes os encontros se davam em reuniōes de pais e mestres e em festas escolares, agora se fala em atendimento aos pais. Um termo notadamente exterior ao campo educativo, comum nas áreas médico-psicológicas. Se antes os alunos tinham boletim de notas e, ao desrespeitarem as regras, tinham que assinar o temido livro negro, atualmente as escolas têm prontuários dos alunos. Chama a atenção não somente o viés médico, mas também policial, que esse termo aponta.

O ideal em questão sustenta a ilusão de que, se conhecermos os alunos de forma integral - sem deixar nada escapar - naturalmente a tarefa educativa será eficiente. Aqui vale lembrar o texto de Freud (1908), Sobre as teorias sexuais das crianças, no qual observamos que a elaboração de tais teorias sexuais revela o interesse infantil por algo do qual elas não participam, como o coito dos pais e a gravidez, sendo que a solução presente nessas teorizações infantis busca como referência o próprio corpo. Os "erros" presentes nas teorias sexuais infantis são fruto de uma intensa elaboração e se, por um lado, não condizem com a verdade dos fatos, por outro, obedecem aos fins narcísicos da criança. Se sua atividade cognoscente impóe-se como desvendamento de um enigma, parece claro que há a necessidade de um descompasso entre a criança e o adulto. Em outras palavras, não há por que teorizar se não há enigmas a serem desvendados. Isso interroga o pretenso conhecimento integral do aluno por parte do professor, que acaba por enrijecer a relação adulto-criança, pois preconiza prescrições, proibições e restrições sempre muito bem fundamentadas cientificamente. $\mathrm{O}$ ato educativo - ao contrário - tem sempre um caráter um tanto arbitrário, $\mathrm{o}$ que impulsiona a criança a desejar para-além de seus pais e mestres. 
Voltando à expressão aluno com necessidades educativas especiais, percebe-se um paradoxo interessante - e revelador. Se a Declaração de Salamanca (1994) determina que "toda criança possui características, interesses, habilidades e necessidades de aprendizagem que são únicas" (grifo meu), destaca-se a singularidade, um estilo de aprender, inapreensível por estrutura e, portanto, nãocategorizável. Uma criança surda não aprende como todas as outras crianças também surdas, o que compromete a categoria deficiente auditivo. Ao utilizar a lógica categorial ao extremo, uma escola com 200 alunos teria, obrigatoriamente, uma lista com 200 estilos de aprender!

Há que se perguntar como o único se transformou em especial. Se a educação inclusiva tem como prerrogativa a inclusão de todos os alunos preferivelmente no ensino regular, por que o termo especial tem tanto destaque? Nos títulos dos documentos oficiais não aparecem os termos inclusão ou educação inclusiva, e

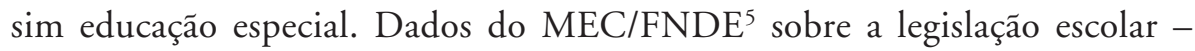
entre 2000 e 2008 - são paradigmáticos. A educação inclusiva aparece no texto da Educação Especial. O termo educação inclusiva somente aparece no título Saúde do Escolar. Já o termo especial, utilizado tanto para designar a educação especial quanto a inclusiva, aparece nos títulos: Biblioteca da Escola; Educação Especial; Saúde do Escolar e Transporte do Escolar. O termo inclusão aparece no título Projetos Educacionais, mas é entendido como a cultura afro-brasileira e/ou o programa nacional de inclusão de jovens.

Esse inconveniente paradoxo - o especial no lugar da inclusão - está explícito na legislação, com a profusão de termos como: serviços de apoio pedagógico especializado; atuação colaborativa de professor especializado em educação especial; classes especiais; professores capacitados e especializados; formação continuada, inclusive em nível de especialização; complementação de estudos ou pós-graduação em áreas específicas da educação especial (LDB, resolução de 2001, grifos meus).

Atendendo à legislação, a escola vê-se invadida por saberes e profissionais especialistas. Em outra reportagem de capa da revista Nova Escola (Gurgel, 2007), "Inclusão, só com aprendizagem" (grifo meu), discute-se o trabalho de professores regentes e especialistas. Estes últimos têm a tarefa de complementação (em relação às deficiências) ou suplementação (no caso da superdotação) curricular. Qual é o padrão implícito? Ao complementar ou suplementar, objetiva-se que todos fiquem iguais a, a partir de um padrão predeterminado. E o espaço para a pluralidade e a diversidade que a educação inclusiva preconiza? Eis aí mais um paradoxo inconveniente. Voltolini (2006) analisa a posição de destaque que se dá ao especialista tanto na educação especi-

5. Fundo Nacional de Desenvolvimento da Educação (FNDE). 
al quanto na inclusiva: "No caso da educação especial de forma direta no trabalho com as crianças. No caso das escolas inclusivas de maneira indireta na formação dos professores para a nova realidade da inclusão”. O autor ainda ressalta:

O fato é que a ênfase na participação do especialista faz parte da estratégia moderna, que de um lado investe na gestão dos problemas sociais através de medidas administrativas e do estabelecimento de políticas gerenciáveis e, de outro lado, que vê no saber científico enquanto aquele que oferece técnicas, o instrumento para isso. (Voltolini, 2006)

Se a educação inclusiva, como vimos, está tão imersa no especial, o que efetivamente mudou? A lógica presente na educação especial, com a presença de especialistas com saberes cada vez mais especializados, em um movimento contínuo de estimulação, readaptação e reabilitação, também aparece nos ideais da educação inclusiva.

No texto da LDB (resolução de 2001), o termo professor vem adjetivado. Há os professores capacitados (que precisam ter algo de especial):

São considerados professores capacitados para atuar em classes comuns com alunos que apresentam necessidades educacionais especiais aqueles que comprovem que, em sua formação, de nível médio ou superior, foram incluídos conteúdos sobre educação especial adequados ao desenvolvimento de competências e valores para:

I - perceber as necessidades educacionais especiais dos alunos e valorizar a educação inclusiva;

II - flexibilizar a ação pedagógica nas diferentes áreas de conhecimento de modo adequado às necessidades especiais de aprendizagem;

III - avaliar continuamente a eficácia do processo educativo para o atendimento de necessidades educacionais especiais;

IV - atuar em equipe, inclusive com professores especializados em educação especial. (Brasil, 2001)

E há os professores especializados:

São considerados professores especializados em educação especial aqueles que desenvolveram competências para identificar as necessidades educacionais especiais para definir, implementar, liderar e apoiar a implementação de estratégias de flexibilização, adaptação curricular, procedimentos didáticos pedagógicos e práticas alternativas, adequados ao atendimentos das mesmas, 
bem como trabalhar em equipe, assistindo o professor de classe comum nas práticas que são necessárias para promover a inclusão dos alunos com necessidades educacionais especiais.(op. cit.)

A educação inclusiva realmente instala um novo paradigma ou impõe a lógica especial a todo o sistema escolar? Lajonquière (1999) chama a atenção para o fato de que o sistema escolar, submetido ao discurso (psico)pedagógico,

[...] pensa a educação como sendo o processo de estimulação do desenvolvimento do dito indivíduo psicológico, ou seja, de um organismo passível de adaptar-se na proporção das interaçōes bem-sucedidas entre as capacidades maturacionais trazidas consigo e os estímulos gratificantes aportados pelo meio. (p. 111, grifos do autor).

Ainda com Lajonquière:

Nesse sentido, a "especialidade" das ditas crianças especiais residiria na falta parcial ou radical de uma ou de várias capacidades psicológicas maturacionais. Portanto, o atributo especial da educação dispensada se reduz a um cuidado redobrado - isto é, especial - no processo de estimulação. Como sabemos, na educação especial coloca-se um cuidado suplementar na seleção dos estímulos, no metodismo de sua apresentação, na identificação da capacidade das "capacidades", na avaliação dos resultados, etc. Assim, o cotidiano "educativo especial” é o paroxismo do processo de psicologização da educação. (op. cit., p. 111, grifos do autor).

Dessa forma, evidencia-se que a apropriação da lógica da educação especial pela educação inclusiva obedece a um discurso (psico)pedagógico hegemônico (Lajonquière, 1998), que se caracteriza por uma premissa totalizante que abarca tanto aspectos preventivos quanto prognósticos, apoiado em um certo cientificismo psicológico ${ }^{6}$.

Nada escapa a esse tipo de discurso, posto que tudo o que ocorre na cena educativa está sujeito a um viés explicativo que convoca um saber tecnocientífico, seja ele representado pela medicina (com suas categorias nosográficas e a consequente medicalização do cotidiano escolar) ou pela psicologia (ao propor um desenvolvimento maturacional). A escola e os pais - suscetíveis a essas

6. Patto (1984; 2002), embora partindo de outras premissas de análise, demonstra de modo contundente como a psicologia auxiliou na justificativa do fracasso escolar das crianças das classes populares e, além disso, como a própria introdução da psicologia no Brasil esteve vinculada à psicologização da aprendizagem escolar. 
influências - acabam por renunciar ao ato educativo (Lajonquière, 1999), demitindo-se - em nome de um racionalismo tecnocientífico - da tarefa de educar. É cada vez mais comum o adulto deixar de agir em nome próprio - o que apresenta um caráter sempre arbitrário - para servir-se desse saber tecnicista, destituindo-se do papel de transmissor de heranças simbólicas. Observa-se, em diversas instâncias sociais, as crianças sendo assistidas pelos adultos, sem que estes exerçam a autoridade de forma legítima. Calligaris (1991) chama esse adulto que recua frente à tarefa educativa, de soft-moderno:

[...] você me obedece porque a ciência razoavelmente demonstra que a minha interdição é bem fundada. Há uma diferença relevante entre proibir a um menino de se dependurar na janela porque está proibido, ou então explicar-lhe que, sendo o peso da cabeça comparativamente maior do que o peso do corpo, Arquimedes demonstrou que não é aconselhável se dependurar na janela. A versão soft compromete o valor simbólico dos laços, pois o próprio do simbólico é que ele é arbitrário: a justificação o enfraquece (op. cit., p. 110).

Lebrun (2004) discute o discurso tecnocientifico presente na atualidade, ressaltando a supervalorização da eficácia e o primado da técnica em relação à teoria. "Só resta aprender a 'gerir' da melhor forma sua eficácia, a valorizar sua gestão. Permite poupar-se da criação e da invenção" (p. 102). O autor coloca alguns efeitos desse discurso, como sua pretensão universalizante, a autoridade dos enunciados e a consequente exclusão do enunciador e o apagamento da conflitualidade. "Passar do regime dos pais para os expertos implica uma nova versão do sonho de servidão voluntária” (p. 128).

Acreditar que tudo está dado a priori, através dos subsídios de um saber tecnocientífico, dificulta (e por vezes impede) uma abertura possível para a interrogação e o inusitado. Se os atores da Educação - a família e a escola não puderem suportar o não-saber, como poderão transmitir o desejo de saber? E ainda: se a família e a escola não se autorizarem a educar - em nome próprio e não subjugadas ao discurso (psico)pedagógico hegemônico - como vão transmitir as heranças simbólicas ? Segundo Arendt (1997), "é com palavras e atos que nos inserimos no mundo humano; e esta inserção é como um segundo nascimento, no qual confirmamos e assumimos o fato original e singular do nosso aparecimento físico" (p. 56). E esse segundo nascimento só é possível através de outros humanos, que não recuem diante da tarefa educativa de introduzir a criança nesse velho mundo (Arendt, 1997a).

Cada um deve se autorizar (e responsabilizar-se) num julgamento, não podendo remeter exclusivamente ao saber dos 
expertos. [...] Uma decisão não é simplesmente consequência do saber, pois ela termina sempre por implicar um ponto de não-saber e essa incerteza, longe de ser um vício, é, ao contrário, o que "deixa a desejar". (Lebrun, 2004, p . 213).

Esse discurso tecnocientifico faz-nos relembrar que a proposta freudiana, diferentemente, é incapaz de construir uma Weltanschauung:

Weltanschauung é uma construção intelectual que soluciona todos os problemas de nossa existência, uniformemente, com base em uma hipótese superior dominante, a qual, por conseguinte, não deixa nenhuma pergunta sem resposta e na qual tudo o que nos interessa encontra seu lugar fixo. (Freud, 1933, p. 193).

Nesse mesmo texto, de 1933, "A questão de uma Weltanschauung", Freud sublinha o fato compreensível de que os seres humanos tenham como ideal a posse de uma Weltanschaunng, pois “acreditando-se nela, pode-se sentir segurança na vida, pode-se saber o que se procura alcançar e como se pode lidar com as emoçôes" (op. cit., p. 193-194). Isso talvez nos ajude a pensar sobre a facilidade com que a Educação abarca em seu interior concepções que lhe são alheias, mas que cumpram o papel de uma Weltanschauung.

É possível considerar que o contemporâneo racionalismo tecnocientífico seja a Weltanschauung dos dias atuais. Esse tecnicismo tem efetivado uma exacerbação da racionalidade instrumental, determinando um tempo que é marcado pelo efêmero, no qual a flexibilidade e a fluidez aparecem como tentativas de acompanhar essa velocidade. No lugar da unidade, a multiplicidade; no lugar da integração, a fragmentação; no lugar do a longo prazo, o aqui-e-agora. $\mathrm{O}$ individualismo, o consumismo e o hedonismo parecem, dessa forma, ser efeitos desse tecnicismo.

A educação inclusiva não está imune a esses efeitos. A Declaração de Salamanca (1994), referendada pela Declaração dos Direitos Humanos (1948), marca um posicionamento crítico frente ao sistema escolar excludente, porém - paradoxalmente - a inclusão tem exacerbado o poder do especialista e privilegiado a eficácia, a funcionalidade e o excesso (de informações, de técnicas e de saberes).

Um exemplo de educação inclusiva que não tem cedido a esses apelos tecnicistas é a Escola Experimental Bonneuil-sur-Marne. "Podemos reconhecer em Maud Mannoni e sua experiência em Bonneuil um pioneirismo em termos de política inclusiva na educação" (Voltolini, 2004, p. 92). Inspirada pelo trabalho dos psicanalistas Jacques Lacan, Donald Winnicott e Françoise Dolto, por algumas experiências e contestaçôes das instituições sociais e das 
realidades educacionais realizadas por Célestin Freinet, Anton Makarenko, Alexander Neill, Ivan Illich e Karl Marx e por seu contexto histórico - especialmente pelo movimento antipsiquiátrico e o Maio de 68 - Maud Mannoni reúne-se com um grupo de amigos psicanalistas e funda em 12 de setembro de 1969 a École Expérimentale Bonneuil-sur-Marne, nos arredores de Paris, a fim de acolher crianças excluídas do sistema regular de ensino. Segundo Lajonquière (1999), as referências precursoras de Bonneuil "[...] possuem algo em comum: a subversão de diferentes aspectos e pontos inerentes ao ideário (psico)pedagógico moderno" (p. 109).

A institution éclatée - instituição estourada - propõe atividades dentro (ateliês diversos; atividades ligadas ao funcionamento da instituição) e fora (nos alojamentos noturnos; nas famílias acolhedoras; nos lugares de trabalho para os adolescentes). Freud (1920, p. 26), ao descrever o jogo do fort-da, ressalta que a entrada da criança no simbólico dá-se através da alternância entre presença e ausência. Esse jogo simboliza o domínio sobre a presença e a ausência da mãe, expresso no lançar e puxar o carretel. Mannoni (1988) afirma que a École de Bonneuil privilegia a alternância e, por isso, denomina-a "instituição estourada". Trata-se de uma referência ao jogo do fort-da. De acordo com Geoffroy (2004, p. 35), "sendo uma instituição, Bonneuil se coloca à disposição, por um lado, como um lugar de recolhimento protegido, mas, por outro, não se cansa de referir que Bonneuil não é tudo, que há um fora da instituição”.

$\mathrm{O}$ diagnóstico das crianças e dos adolescentes recebidos em Bonneuil não tem função classificatória e muito menos determinam a priori o percurso delas na instituição (seja na escolha das atividades, seja no contato com os adultos). Dessa forma, como ressalta Geoffroy (op. cit.), utiliza-se a expressão crianças e adolescentes em dificuldade:

O pensamento de que uma instituição atenda a alguém opõe-se ao princípio de Bonneuil. Bonneuil recebe "des enfants et des jeunes en difficulté", ou seja, crianças e adolescentes em dificuldade. Neste caso, o acento encontra-se no "em" porque este "em" indica - ao contrário da expressão "crianças com dificuldade" — que se trata de uma condição que pode ser alterada, e não de uma maneira de ser do sujeito que seja imutável. (p. 27-8)

A presença constante de estagiários estrangeiros em Bonneuil, que muitas vezes não dominam bem o francês, é uma tentativa de evitar o discurso institucional totalizante, hegemônico. De acordo com Mannoni (1995):

[...] qualquer lugar, por mais "original" que tenha sido em sua fundação, só pode continuar à escuta dessas crianças quando a equipe é renovada por uma presença suficiente de estagiários 
estrangeiros, que venham questioná-la a partir de uma cultura e um lugar diferentes. (p. 74, grifos do autor).

$\mathrm{Na}$ contramão da escola inclusiva especializada, Bonneuil parece apontar para a possibilidade de uma educação para todos, sem transformá-la em uma educação especial para cada um.

Longe de propor técnicas e modelos a serem seguidos, pretende-se inserir na discussão acerca da educação inclusiva alguns questionamentos que, a princípio, têm sido muito pouco contemplados. Os fenômenos que têm sido objeto de estudo na área indicam a polarização entre educação inclusiva e educação especial. O enfoque do presente trabalho é apontar os pressupostos de tal polarização, numa tentativa de evidenciar alguns paradoxos que parecem muito mais aproximar do que afastar a educação inclusiva da lógica clássica da educação especial.

\section{Referências bibliográficas}

AGAMBEN, G. Homo sacer-o poder soberano e a vida nua. Belo Horizonte: UFMG, 2004. 207 p.

ANDRÉ, S. O que quer uma mulher? Rio de Janeiro: Jorge Zahar, 1998. 295 p.

ARENDT, H. A condição humana. 10. ed. Rio de Janeiro: Forense Universitária, 1997. 352 p.

ARENDT, H. Entre o passado e o futuro. 4. ed. São Paulo: Perspectiva, 1997a. 348 p.

BAUMAN, Z. Modernidade e ambivalência. Rio de Janeiro: Jorge Zahar, 1999. 335 p.

BRASIL. Lei de Diretrizes e Bases da Educação Nacional. Lei no 9.394/96, de 20 de dezembro de 1996.

BRASIL. Secretaria de Educação Especial. Brasília, MEC/SEESP, 1997.

BRASIL. Decreto n ${ }^{\circ} 3.298$, de 20 de dezembro de 1999. Secretaria Especial de Direitos Humanos/Corde - Coordenadoria Nacional para Integração da Pessoa Portadora de Deficiência. Disponível em: http://www.mj.gov.br/sedh/ct/corde/dpdh/corde/dec3298.asp. Acesso em : 30 de setembro de 2008 .

BRASIL. Lei de Diretrizes e Bases da Educação - LDB Legislação Educação EspecialResolução no 2, de 11 de setembro de 2001. Disponível em: <http://www.ismart.org.br/downloads/ ldb_destacada.pdf>. Acesso em: 30 set. 2008

BRASIL. Censo Escolar 2006. MEC/Inep. Disponível em: http://www.inep.gov.br/ Acesso em: 30 de setembro de 2008.

BRASIL. Fundo Nacional de Desenvolvimento da Educação - legislação, MEC/FNDE. Disponível em: http://www.fnde.gov.br/home/index.jsp?arquivo=legislacao.html. Acesso em: 28 de set. 2008. 
CALLIGARIS, C. Hello Brasil! Notas de um psicanalista europeu viajando ao Brasil. São Paulo: Escuta, 1991. 173 p.

FREUD, S. Sobre as teorias sexuais das crianças. In: FREUD, S. Edição standard brasileira das obras psicológicas completas de Sigmund Freud. Trad. de J. Salomão. Rio de Janeiro: Imago, 1980 (original de 1908). p. 211-228. v. 9.

FREUD, S. Totem e tabu. In: FREUD, S. Edição standard brasileira das obras psicológicas completas de Sigmund Freud. Trad. de J. Salomão. Rio de Janeiro: Imago, 1980 (original de 1913). p. 13-191. v. 13.

FREUD, S. O estranho. In: FREUD, S. Edição standard brasileira das obras psicológicas completas de Sigmund Freud. Trad. de J. Salomão. Rio de Janeiro: Imago, 1980 (original de 1919). p. 273-318. v. 17.

FREUD, S. Além do princípio do prazer. In: FREUD, S., Edição standard brasileira das obras psicológicas completas de Sigmund Freud. Trad. de J. Salomão. Rio de Janeiro: Imago, 1980 (original de 1920). p. 13-85. v. 18.

FREUD, S. Conferência XXXV: A questão de uma Weltanschauung. In: FREUD, S. Edição standard brasileira das obras psicológicas completas de Sigmund Freud. Trad. de J. Salomão.). Rio de Janeiro: Imago, 1980 (original de 1933). p. 193-220. v. 22.

GEOFFROY, M. A. A “instituição estourada” como “jogo do fort-da” - de Jacques Lacan ao conceito de "instituição estourada” da Escola Experimental de Bonneuil-sur-Marne. Trad. de Kelly Cristina Brandão da Silva. Estilos da Clínica: Revista sobre a infância com problemas, São Paulo, v. 9, n. 17, $2^{\circ}$ semestre de 2004, p. 26-5, 2004.

GUIMARÃES, A. A inclusão que funciona. Revista Nova Escola, São Paulo, n. 165, set. 2003. Disponível em: <http://revistaescola.abril.com.br/edicoes/0165/aberto/mt_188945.shtml>. Acesso em: 30 set. 2008.

GURGEL, T. Inclusão, só com aprendizagem. Revista Nova Escola, São Paulo, n. 206, out. 2007. Disponível em: <http://revistaescola.abril.com.br/edicoes/pdf/0206/inclusao.pdf>. Acesso em: 30 set. 2008.

LACAN, J. Seminário 17: o avesso da psicanálise. Rio de Janeiro: Jorge Zahar, 1992. 209 p.

LAJONQUIÈRE, L. A psicanálise, a educação e a escola de Bonneuil. A (à) lembrança de Maud Mannoni. Estilos da Clínica: Revista sobre a infância com problemas, São Paulo, ano 3, n. 4, p. 65-79, 1998.

LAJONQUIÈRE, L. Infância e ilusão (psico)pedagógica: escritos de psicanálise e educação. 3. ed. Petrópolis, RJ: Vozes, 1999. 204 p.

LAJONQUIÈRE, L. Duas notas psicanalíticas sobre as crianças "com necessidades educativas especiais”. Pro-Posiçôes, Campinas, v. 12, n. 2-3 (35-36), p. 47-59, jul.-nov., 2001.

LEBRUN, J. P. Um mundo sem limite: ensaio para uma clínica psicanalítica do social. Rio de Janeiro: Companhia de Freud, 2004. 214 p.

MANNONI, M. Educação impossivel. 2. ed. Rio de Janeiro: Francisco Alves, 1988. 317 p. 
MANNONI, M. Amor, ódio, separação: o reencontro com a linguagem esquecida da infância. Rio de Janeiro: Jorge Zahar, 1995.137 p.

PATTO, M.H.S. Psicologia e ideologia. São Paulo: T.A. Queiroz, 1984. 229 p.

PATTO, M.H.S. A produção do fracasso escolar: histórias de submissão e rebeldia. 2. ed. São Paulo: Casa do Psicólogo, 2002. 458 p.

VOLTOLINI, R. Psicanálise e inclusão escolar: direito ou sintoma? Estilos da Clínica: Revista sobre a infância com problemas. São Paulo, v. 9, n. 16, p. 92-101, 2004.

VOLTOLINI, R. A inclusão conduz ao pior. In: COLÓQUIO DO LEPSI IP/FE-USP, 5, 2006, São Paulo. (Não paginado). Disponível em: <http://www.proceedings.scielo.br/ scielo.php?script=sci_arttext\&pid=MSC0000000032006000100009\&lng=en\&nrm=abn>. Acesso em 5 ago. 2007.

UNESCO. Declaração de Salamanca, 1994. Disponível em: <http://portal.mec.gov.br/seesp/ arquivos/pdf/salamanca.pdf>. Acesso em: 30 set. 2008.

UNESCO. Declaração Universal dos Direitos Humanos, 1948. Disponível em: <http:// www.mj.gov.br/sedh/ct/legis_intern/ddh_bib_inter_universal.htm>. Acesso em: 30 set. 2008.

Recebido em 02 de março de 2009 e aprovado em 05 de agosto de 2009. 